\title{
A PANDEMIA DO NOVO CORONAVÍRUS (COVID-19): CONSIDERAÇÕES SOBRE O NEOLIBERALISMO E O ESTADO DE BEM-ESTAR SOCIAL NAS AÇÕES GOVERNAMENTAIS
}

Marcus Alexandre de Pádua Cavalcanti Bastos Doutor em Educação em Ciências e Saúde pela Universidade Federal do Rio de Janeiro (UFRJ), Rio de Janeiro, RJ, Brasil marcus_nathan1203@hotmail.com

Eliane Cristina Tenório Cavalcanti Doutoranda em Educação em Ciências e Saúde pela Universidade Federal do Rio de Janeiro (UFRJ), Rio de Janeiro, RJ, Brasil eliane.cavalcanti@hotmail.com

Elisabeth Almenara da Silva Bacharel em Pedagogia e Licenciatura em Estudos Sociais pela Universidade do Estado do Rio de Janeiro (UERJ), Rio de Janeiro, RJ, Brasil ealmenaradasilva@gmail.com

Nathan da Costa Cavalcanti Bastos Bacharelando em Farmácia, Universidade Estácio de Sá (UNESA), Rio de Janeiro, RJ, Brasil nathan-psytrance@hotmail.com

\section{RESUMO}

A crise gerada pelo novo coronavírus traz preocupações cada vez maiores entre as nações de todos os continentes e já altera profundamente as relações políticas e econômicas em escala global. Os impactos causados pela pandemia do coronavírus têm feito com que os países revejam suas políticas públicas e levantem questionamentos sobre o sistema capitalista enquanto sistema social predominante. Destarte, o presente artigo tem como objetivo apontar a importância do Estado de Bem-estar Social, seus benefícios em relação às políticas públicas, como é o caso do serviço de saúde pública. Nesse artigo, partimos do pressuposto de que a pandemia gerada pelo coronavírus expõe a fragilidade do modelo neoliberal brasileiro na contenção da crise, uma vez que esse modelo preconiza uma drástica redução do papel do Estado na economia favorecendo o setor privado. Concluímos que a pandemia do coronavírus vem apontando a precariedade do neoliberalismo com o avanço do novo coronavírus, há um reposicionamento do papel do Estado, que a partir da crise, vem adotando práticas de gestão políticas baseadas no Welfare State, um modelo social, político e econômico solidário que garante a todos os cidadãos, independentemente da idade ou classe social, padrões mínimos de saúde e seguridade social.

Palavras-chave: Pandemia. Welfare state. Neoliberalismo. 


\title{
THE NEW CORONAVIRUS PANDEMIC (COVID-19): CONSIDERATIONS ON NEOLIBERALISM AND THE STATE OF SOCIAL WELFARE IN GOVERNMENTAL ACTIONS
}

\begin{abstract}
The crisis generated by the new coronavirus raises growing concerns among nations on all continents and is already profoundly altering political and economic relations on a global scale. The impacts caused by the coronavírus pandemic have caused countries to review their public policies and raise questions about the capitalist system as the predominant social system. There is a repositioning of some States in the sense of adopting a social, political and economic model that guarantees to all citizens minimum standards of health and social security. Thus, this article aims to point out the importance of the Social Welfare State, its benefits in relation to public policies, as is the case with the public health service. In this article, we assume that the pandemic generated by the coronavirus exposes the fragility of the Brazilian neoliberal model in containing the crisis, since this model calls for a drastic reduction in the role of the state in the economy, favoring the private sector. In order to pave the way for a reflection on this issue, we will take as a basis the dialectical materialism that proposes a search for the explanation of the phenomena of reality from strictly concrete conditions. The article was developed from bibliographic research with a qualitative approach.
\end{abstract}

Keywords: Pandemic. Welfare state. Neoliberalism. 


\section{INTRODUÇÃO}

A crise de saúde gerada pelo novo coronavírus vem trazendo preocupações cada vez maiores entre as nações de todos os continentes e já altera profundamente as relações políticas e econômicas em escala global. A Covid-19², como é chamada oficialmente, se espalhou pelo mundo trazendo impactos em toda economia mundial.

Os primeiros casos suspeitos foram notificados em 31 de dezembro de 2019 em Wuhan, província de Hubei, na China. A escalada do surto originado na cidade chinesa se espalhou pelo mundo. No dia 21 de janeiro de 2020, os Estados Unidos reportaram seu primeiro caso. Em 30 de janeiro de 2020, a Organização Mundial da Saúde (OMS) declarou Emergência de Saúde Pública de Importância Internacional (ESPII) em razão da disseminação do coronavírus. Ao final do mês de janeiro, diversos países já haviam confirmado alguns casos, incluindo Estados Unidos, Canadá, Austrália e Brasil. Com o aumento dos casos e disseminação da Covid-19, a Organização Mundial da Saúde declarou em 11 de março de 2020 que o mundo enfrenta uma pandemia do novo coronavírus (LANA et al., 2020).

Um fato importante a ser observado na crise da Covid-19 é que os países que possuem um sistema de seguridade social forte, com sistemas de cobertura de saúde universais vêm tendo maior controle e efetividade sobre a pandemia. As estratégias e práticas de contenção adotadas pela China e outros países como Japão e Coréia do Sul tem se mostrado eficazes no combate e na redução da pandemia. Esses países estão se saindo melhor em lidar com a crise do que os Estados Unidos, onde não há rede de proteção social.

Em um relatório recente da OMS (Organização Mundial da Saúde) de fevereiro deste ano, são apresentados dados de grande interesse sobre como essa pandemia deve ser respondida, e a relação com as condições dos serviços de saúde e outros serviços sociais. Entre as condições que favorecem uma resposta positiva à pandemia está o nível de solidez de tais sistemas de saúde, bem como a estratégia para atacar a epidemia. Isso inclui ser

\footnotetext{
2 Os coronavírus (CoV) são uma grande família viral, conhecidos desde meados dos anos 1960, que causam infecções respiratórias em seres humanos e em animais. Geralmente, infecções por coronavírus causam doenças respiratórias leves a moderada, semelhantes a um resfriado comum. A maioria das pessoas se infecta com os coronavírus comuns ao longo da vida. Todos os coronavírus são transmitidos de pessoa a pessoa, incluindo os SARS-CoV, porém sem transmissão sustentada. Alguns coronavírus podem causar síndromes respiratórias graves, como a síndrome respiratória aguda grave que ficou conhecida pela sigla SARS da síndrome em inglês "Severe Acute Respiratory Syndrome". SARS é causada pelo coronavírus associado à SARS (SARS-CoV), sendo os primeiros relatos na China em 2002. O SARS-CoV se disseminou rapidamente para mais de doze países na América do Norte, América do Sul, Europa e Ásia.
} 
capaz de detectar pessoas infectadas e cuidar de quem tem e desenvolve a doença, garantindo que a capacidade do sistema de saúde seja mantida para atender adequadamente o número de pacientes, garantindo que eles tenham recursos profissionais suficientes para atender toda a população. A existência de cada uma dessas características é um indicador do compromisso público e coletivo à solidariedade diante de uma ameaça comum que a sociedade deve enfrentar.

Com o objetivo de abrir caminho para uma reflexão acerca das contradições existentes entre o neoliberalismo e o walfare state na gestão do coronavírus, tomaremos como base o materialismo histórico que propõe a busca pelas explicações dos fenômenos da realidade a partir de condições estritamente concretas. O materialismo propõe que todos os fenômenos sociais e econômicos devem ser analisados dentro de seu historicismo e do contexto da vida social e material produzida pelos homens (MARX, 2008). Para Marx, "o concreto é concreto porque é a síntese de múltiplas determinações" (MARX, 2008, p. 258), por isso o concreto aparece na abstração como processo de síntese, as determinações resultantes do pensamento conduzem a representação por meio da abstração e estas são percebidas como resultado e não como premissas. Compreendemos que sendo a desigualdade o fato justificador da política social burguesa e a igualdade o seu parâmetro idealizado, nenhuma teoria poderia fornecer maiores subsídios à crítica dessa política do que a marxiana. Isso porque, parafraseando Mishra (2018), ela é a única teoria que aborda a questão da desigualdade de forma abrangente, isto é, tanto nas suas dimensões econômica, política e social, quanto nas suas versões capitalista e socialista.

O artigo foi desenvolvido a partir de pesquisa bibliográfica com abordagem qualitativa e está organizado em três partes. Na primeira parte destacamos os aspectos conceituais do que se pode chamar de welfare state, quais suas características fundamentais e como pode ter sido constituído em alguns tipos de sociedades. A segunda parte discute as implicações do neoliberalismo na organização atual das sociedades capitalistas. Por último, apontamos como a pandemia do coronavírus se tornou uma oportunidade para evidenciar a incapacidade que o neoliberalismo tem para lidar com esse tipo de problema. 


\title{
20 ESTADO DE BEM-ESTAR SOCIAL - WELFARE STATE
}

\section{A criação do estado de bem-estar social ocorreu em um momento histórico} marcado pelo crescimento econômico e redução das desigualdades sociais. O Welfare State ${ }^{3}$ (Estado de Bem-estar Social) é um modelo social, político e econômico desenvolvido em 1936 pelo economista britânico John Maynard Keynes4 que garante a todos os cidadãos, independentemente da idade ou classe social, padrões mínimos de saúde, educação, habitação e seguridade social (VIANA; LEVCOVITZ, 2010).

De acordo com Leme (2010), os princípios fundamentais do Welfare State são os seguintes:

A seguridade social (é um amparo ao trabalhador caso ocorra algum imprevisto, e ele perca temporária ou definitivamente sua capacidade de gerar renda); a ampliação das oportunidades de emprego e renda - garantia do pleno emprego, o que geraria a chamada Demanda Efetiva; e, por fim, a ampliação das políticas sociais, enfim, políticas redistributivas e compensatórias, que tem o objetivo de minimizar as desigualdades sociais (LEME, 2010, p. 210).

A proposta keynesiana, segundo Candiotto (2012, p. 160):

\begin{abstract}
Consiste basicamente na reformulação macroeconômica do liberalismo, por meio do vínculo do consumo à função de renda. Ao ser aumentado o nível de renda, cresce a propensão a poupar e diminui-se a proporção de renda gasta no consumo. Este vínculo proporcionou ao capitalismo um modelo de equilíbrio ao permitir que a micro e a macroeconomia funcionassem pelo predomínio da economia privada. Keynes defende ser possível superar as crises cíclicas do capitalismo por meio do crescimento e manutenção dos empregos e do incremento dos gastos públicos com políticas sociais adequadas e equânimes (CANDIOTTO, 2012, p. 160).
\end{abstract}

O estado de bem-estar social ${ }^{5}$ é, também, o responsável pela regulamentação e garantia das leis trabalhistas e pelo direito à previdência social. Para garantir tais direitos

\footnotetext{
${ }^{3}$ Esse modelo foi desenvolvido em 1936 pelo economista britânico John Maynard Keynes (1883-1946) que publicou o livro A Teoria Geral do Emprego, do Juro e da Moeda. O papel intervencionista do Estado decorre das diversas inconsistências que se apresentam no modelo liberal, assentadas, sobretudo, a) na Revolução Industrial, com implicações na proletarização; b) na Primeira Guerra Mundial, que rompe com a tradição do liberalismo econômico; c) na necessidade de intervenção na economia em decorrência da crise de 1929, conciliando a iniciativa privada e a ação governamental; d) na Segunda Guerra Mundial, que impôs a necessidade de um Estado controlador de recursos sociais; e) nas crises cíclicas da economia; f) na insubsistência do ideal da livre força do mercado; g) na alteração paradigmática entre da liberdade negativa para a liberdade positiva ou liberdades sociais (STRECK, 2010).

${ }^{4} \mathrm{O}$ Welfare State, marcado pelo pensamento keynesiano passou a ter força a partir dos anos 40 - período pós Segunda Guerra) até os anos 70, a partir de então, uma série de eventos marcaria o início de uma importante crise fiscal dos Estados Nacionais (CANDIOTTO, 2012).

${ }^{5}$ Os estudiosos do Estado de Bem-Estar vêm utilizando como indicador, de maneira a estabelecer a intensidade do Estado de Bem-Estar em um determinado país, o nível de gasto público e, em particular, de gasto com o
} 
sociais básicos, é preciso da intervenção do Estado na economia, a fim de garantir a geração e regulação de empregos, manutenção das leis e garantia de melhoria no padrão de vida dos cidadãos (ESPING-ANDERSEN, c1990).

Neste modelo, o governo deve garantir aos indivíduos o que é conhecido, no Brasil, como direitos sociais, ou seja, condições mínimas nas áreas de saúde, educação, habitação, seguridade social, entre outras. Ademais, em momentos de crise e de desemprego, o Estado deve intervir na economia de forma que se busque a manutenção da renda e do trabalho das pessoas prejudicadas com a situação do país.

Os sistemas de proteção social estão no cerne dos Estados, pois estes sistemas buscam harmonizar um problema comum a todas as sociedades capitalistas, a tensão das relações sociais e dos interesses privados, que no Estado de Bem-Estar Social, em maior ou menor medida, são subjugados ao interesse público (REIS, 2009).

O modelo de Seguridade Social, ligado ao modelo do Estado de Bem-Estar é inspirado no princípio de justiça social que busca estender a todos os cidadãos o direito a um mínimo socialmente estabelecido e assegurado pelo Estado. Este modelo é marcado por uma prévia igualdade, tanto do ponto de vista do poder como da distribuição das riquezas produzidas socialmente (REIS, 2009).

Rodrigues (2016, p. 233) afirma que os impactos das políticas sociais podem ser de três tipos, a saber:

\begin{abstract}
Social, redistributivo e econômico. Onde o primeiro diz respeito as alterações nos indicadores sociais como índices relacionados a saúde, educação, entre outros, sua mensuração se faz com a observação das mudanças apresentadas pelo público alvo entre a situação prévia e a situação após o início da política. O Segundo impacto refere-se à valorização econômica de bens e serviços que são transferidos a população, tem mensuração atrelada à incidência em que a referida valorização alcança no ingresso do número total dos lares. Por fim, o impacto econômico, trata dos benefícios e/ou perdas econômicas gerados pelos investimentos das políticas sociais nos diversos agentes, de forma direta ou indireta (RODRIGUES, 2016, p. 233)
\end{abstract}

Lobato (2016) ao analisar a emergência e principalmente o desenvolvimento dos regimes de bem-estar na América Latina cita três períodos distintos. O primeiro, da emergência e constituição dos regimes, relaciona-os à especificidade do capitalismo na

setor social. Este indicador se apresenta como um percentual sobre o conjunto da riqueza produzida pelo país (Produto Interno Bruto - PIB). Na maioria dos países que adotam este modelo de Estado, o conjunto do gasto público tem chegado a representar entre 40 a 50\% do PIB. Em alguns países, como os escandinavos, exemplos de Estado de Bem-Estar, este percentual tem superado os 50\% (cinqüenta por cento) (CANDIOTTO, 2012). 
região e seu correlato modelo de industrialização por substituição de importações, que resulta em um padrão centrado em modelos corporativos, tendo como característica mais comum a estratificação de clientelas e benefícios e amplas camadas da população excluídas. O segundo período de reformas neoliberais, em que os sistemas sofreram mudanças significativas em diversos países durante as décadas de 1980 e 1990, tendendo ou à quebra dos regimes, mas com alternativas diversas como a ampliação da universalização, caso do Brasil.

O terceiro período, mais recente, é identificado com a introdução de modelos econômicos chamados neodesenvolvimentistas, com foco na intervenção estatal e ampliação de políticas sociais. A tendência comum à América Latina foi a introdução do tema da pobreza na agenda pública dos governos, com a criação ou ampliação de programas de transferência de renda e ampliação da cobertura para sistemas de educação, saúde e previdência social. O resultado comum foi a redução significativa da desigualdade, se considerado o padrão histórico da região, além de um crescimento econômico não registrado em outras regiões (LOBATO, 2016).

O autor aponta ainda um quarto período que pode estar se delineando, ele é caracterizado por retração econômica, crise política e econômica e crescimento de governos conservadores, cuja pauta inclui mudanças importantes nas políticas sociais. Embora a análise desse momento seja precoce, já é possível identificar que, novamente, as políticas sociais têm papel central.

\section{O PROJETO NEOLIBERAL E A QUESTÃO DO ESTADO MÍNIMO}

O neoliberalismo ${ }^{6}$ é uma doutrina econômica e política que surgiu no século XX com base em teorias formuladas pelo economista austríaco Friedrich Hayek ${ }^{7}$. A teoria neoliberal

\footnotetext{
${ }^{6} \mathrm{O}$ pensamento liberal do final do século XX, comumente denominado de neoliberalismo, reapareceu logo após a Segunda Guerra Mundial, em contraposição às políticas keynesianas e sociais democratas, que estavam sendo implementadas nos países centrais. Inicialmente surgiu de forma tímida por meio da divulgação de textos como 0 caminho da servidão de Frederich Hayek, de 1944, e "A sociedade aberta e seus inimigos", de Popper, em 1945. Na década de 1960 outras publicações se seguiram, dando sustentação a essa perspectiva, como "Os fundamentos da liberdade" de Frederich Hayek, em 1960, e "Capitalismo e liberdade" de Milton Friedman, publicado em 1962 (ANDERSON, 1995).

7 Para Anderson (1995, p. 9), a obra O Caminho da Servidão (1946), de Friedrich Hayek, escrita em 1944, marca o nascimento do neoliberalismo na Europa e na América do Norte. Neste texto, Hayek firma-se contra o planejamento econômico coletivista do Estado, predominante, segundo o autor, nas sociedades alemã e
} 
surge para opor-se à teoria keynesiana de bem-estar social e do Estado intervencionista. Ele propõe uma nova leitura da parte econômica do liberalismo clássico ${ }^{8}$, tendo como base uma visão econômica conservadora que pretende diminuir ao máximo a participação do Estado na economia (ANDERSON, 1995).

O modelo neoliberal ${ }^{9}$ sublinha a desregulamentação econômica, a flexibilização dos mercados e a desburocratização do Estado. Ao adotar as ideias de Hayek, o neoliberalismo sublinha a não interferência do estado nas questões econômicas e sociais e reduz a democracia somente a um meio desejável para a defesa daliberdade individual de produzir e consumir (ANDERSON, 1995).

O neoliberalismo (liberalismo com novas roupagens) apresentou uma fórmula para a crise, assentada em:

\begin{abstract}
Um Estado forte para romper o poder dos sindicatos e controlar a moeda; 2) um Estado parco para os gastos sociais e regulamentações econômicas; 3) a busca da estabilidade monetária como meta suprema; 4) uma forte disciplina orçamentária, diga-se, contenção dos gastos sociais e restauração de uma taxa natural de desemprego; 5) uma reforma fiscal, diminuindo os impostos sobre os rendimentos mais altos; e 6) o desmonte dos direitos sociais, implicando na quebra da vinculação entre política social e esses direitos, que compunha o pacto político do período anterior (BEHRING, 2009, p. 8).
\end{abstract}

Segundo Anderson (1995), a pretensão do neoliberalismo era "manter um Estado forte, sim, em sua capacidade de romper o poder dos sindicatos e no controle do dinheiro, mas parco em todos os gastos sociais e nas intervenções econômicas" (ANDERSON, 1995, p. 11). Essa proposta advinda dos teóricos neoliberais é associada a um discurso da ineficácia da intervenção do Estado e do Welfare State, como modelo de proteção social, para a prosperidade de todos, que caiu muito bem em um contexto de crise estrutural do

italiana, além das sociedades socialistas, no período que antecedia e durante o próprio transcurso da Segunda Guerra Mundial.

8 O liberalismo passou a constituir os pensamentos políticos e econômicos europeus no fim do século XVIII. Adam Smith (1723-1790), considerado o principal representante do liberalismo Econômico, adota o pensamento que cada homem é capacitado a avaliar suas ações, e aponta o papel da não intervenção demasiada do Estado sobre o mercado, defende a livre concorrência econômica e a geração de riqueza.

${ }^{9}$ O modelo neoliberal tem sua visibilidade maior, primeiro na Inglaterra e, depois, nos EUA. Em 1979, com o governo inglês da primeira-ministra Margareth Thatcher, inicia-se ampla desregulamentação do Estado e irrestrito programa de privatizações. Um dos seus efeitos econômicos nos EUA é o aumento do déficit público devido à competição militar com a ex-União Soviética. Apesar disso, rapidamente o pensamento neoliberal estende-se aos demais países da Europa ocidental, ajudados por uma forte reação da direita liberal. A prioridade do pensamento econômico neoliberal na década de setenta foi, de um lado, deter a inflação, via estabilidade monetária; e, de outro, propiciar a reanimação do capitalismo avançado mundial ao restaurar as taxas de crescimento estáveis. 
capitalismo. "O anticomunismo passava a ter um apelo forte, sensibilizando setores significativos da sociedade que até então não davam ouvidos às advertências sobre o perigo vermelho" (MOTTA, 2002, p. 105).

Inicia-se então, uma ampla desregulamentação do Estado e irrestrito programa de privatizações. Em 1980, no governo norte-americano de Ronald Reagan, o neoliberalismo é invocado para "combater o comunismo, entendido como o "império do mal" (MOTTA, 2002, p. 12).

Nas palavras do próprio Karl Marx, o comunismo foi efetivamente um espectro rondando a sociedade capitalista, uma ameaça a esse modo de produção. No entanto, embora tal afirmação tenha sido feita em meados do século XIX, ela se aplica melhor ao século atual, quando o fantasma do comunismo adquiriu um poder sem precedentes de amedrontar os setores mais conservadores da sociedade. Durante os cerca de 70 anos compreendidos entre a Revolução de outubro de 1917 e a crise do socialismo real ocorrida na virada da década de 1980 para 1990, o comunismo tornou-se muito mais que um espectro (MOTTA, 2002).

A força do comunismo, consubstanciada na expansão e crescimento dos partidos e ideais comunistas, engendrou o anticomunismo. Os grupos sociais atemorizados pela "ameaça" ou "perigo" comunista, por sinal expressões reveladoras de seu estado de espírito, trataram de organizar-se e articular uma contra-ofensiva visando combater o projeto revolucionário (MOTTA, 2002, p. 5).

Com o desmanche acelerado da União Soviética, no fim do século $X X$, e com a crise do socialismo real, Francis Fukuyama (1992, p. 80) declarou:

O fim do Marxismo e dos diferentes tipos de regimes surgidos no curso da história da humanidade, desde monarquias e aristocracias até as teocracias religiosas e as ditaduras fascistas e comunistas deste século, a única forma de governo que sobreviveu intacta até o fim do século XX foi a democracia liberal (FUKUYAMA, 1992, p. 80).

O pensamento neoliberal estende-se aos demais países da Europa ocidental, ajudados por uma forte reação da direita liberal. A prioridade do pensamento econômico neoliberal na década de setenta foi, de um lado, deter a inflação, via estabilidade monetária; e, de outro, propiciar a reanimação do capitalismo avançado mundial ao restaurar as taxas de crescimento estáveis.

As ideias neoliberais chegaram à América Latina ainda na década de 1970. O Chile foi o primeiro país a aderir à nova política, seguido pelo México, Argentina Venezuela e Peru. 
No Brasil, o neoliberalismo foi difundido em 1990 com o então presidente eleito Fernando Collor, que lançou um plano com o objetivo de controlar a inflação. No período houve o início das privatizações, e várias empresas do Brasil foram negociadas. Segundo Filgueiras, "o Governo Collor de Mello foi o último país da América Latina a aderir e a implementar o projeto político-econômico neoliberal, sistematizado doutrinariamente em 1989, de forma inequívoca, pelo chamado Consenso de Washington ${ }^{10 "(F I L G U E I R A S, ~ 2003, ~ p . ~ 84) . ~}$

O presidente da república Fernando Henrique Cardoso (1995/2002) deu continuidade ao projeto neoliberal ${ }^{11} \mathrm{e}$ adotou uma série de medidas que visavam à redução de gastos do Estado, como as privatizações dos setores públicos das telecomunicações (Telebrás), das mineradoras, como a Companhia Siderúrgica Nacional de Volta Redonda e a Companhia Vale do Rio Doce. Além disso, abriu a economia brasileira para o mercado internacional (FIORI, 1997).

$\mathrm{Na}$ perspectiva de Fernando Henrique Cardoso era preciso que o Estado não somente sustentasse a competitividade, mas também se reestruturasse, visando implementar uma administração pública gerencial que deveria se orientar pela eficiência e qualidade dos serviços. (FALEIROS, 2004).

Madeiro (2013, p. 21) afirma que:

As orientações das políticas sociais foram permeadas a partir do receituário acumulação flexível/neoliberalismo, que se constituem pela racionalização dos recursos, pela descentralização participativa e pela focalização dos serviços

\footnotetext{
${ }^{10} \mathrm{O}$ termo Consenso de Washington tem origem num conjunto de regras básicas, identificadas pelo economista John Williamson em 1990, baseadas no pensamento político e opiniões que ele acreditava reunirem consenso amplo naquela época. O conjunto de medidas incluía: 1) disciplina fiscal; 2) redução dos gastos públicos; 3) reforma tributária; 4) determinação de juros pelo mercado; 5) câmbio dependente igualmente do mercado; 6) liberalização do comércio; 7) eliminação de restrições para o investimento estrangeiro direto; 8) privatização das empresas estatais; 9) desregulamentação (afrouxamento das leis económicas e do trabalho); 10) respeito e acesso regulamentado à propriedade intelectual. A referência a "consenso" significou que esta lista foi baseada num conjunto de ideias partilhadas, na época, pelos círculos de poder de Washington, incluindo o Congresso e a Administração dos Estados Unidos da América (Tesouro e Federal Reserve Bank), por um lado, e instituições internacionais com sede em Washington, tais como o FMI e o Banco Mundial, por outro, apoiados por uma série de grupos de reflexão e economistas influentes (LOPES, 2011).

${ }^{11}$ Esse modelo político neoliberal adotado por Fernando Henrique tem seus princípios fundamentados no Consenso de Washington, um encontro ocorrido na capital dos Estados Unidos, programado por economistas de instituições financeiras como o Fundo Monetário Internacional, FMI e o Banco Mundial, no qual se buscava avaliar as reformas econômicas na América Latina. As ideias dos princípios do consenso de Washington sustentam a ideologia neoliberal e podem ser interpretadas como globalizantes porque geram uma coesão no contexto econômico mundial justamente por trazer aos mercados abertura de negociações estimulando os investimentos externos diretos. Essa ação de conexão mundial não é só no âmbito econômico, mas tem ao mesmo tempo uma dimensão política, social e também cultural.
} 
públicos. Reiteramos que tais propostas foram elaboradas e induzidas por agências internacionais como o Banco Mundial e o FMI, segundo as quais, tais propostas poderiam fazer da política social neoliberal um verdadeiro instrumento de erradicação da pobreza na América Latina (MADEIRO, 2013, p. 21).

No Brasil, a agenda neoliberal aprofundada por Bolsonaro mostra sua incompatibilidade com a democracia, com os direitos sociais, com a saúde e com a educação pública. Seu governo tem favorecido políticas de austeridade que reduziu benefícios sociais e aumentou a desigualdade. A estratégia do governo consiste em adotar medidas que desprezem a vida da população mais vulnerável (de baixa renda e os idosos) em favor de uma pequena fração da burguesia (financeira, comercial e agroindustrial), que fornece apoio político ao governo.

Nesse sentido, várias medidas foram tomadas para reduzir a proteção do Estado como a redução do fluxo de recursos orçamentários para educação e saúde pública, desmantelamento de universidades públicas e Sistema Único de Saúde, cortes drásticos no orçamento para ciência e tecnologia, interrupção do serviço público. Todas essas medidas visavam atender à Emenda Constitucional ${ }^{12} 95$ (EC-95) que pavimentaram o caminho para a pandemia se alastrar no país. A Emenda Constitucional congelou gastos sociais e investimentos públicos por vinte anos e liberou despesas financeiras, com juros e amortizações da dívida pública, com o objetivo de gerar superávits primários. O objetivo, segundo Menezes (2020), é honrar compromissos com a fração da burguesia financeira e rentista, independentemente da situação econômica e social do país. Um sinal claro de que no governo Bolsonaro o cuidado ou a proteção do Estado é direcionado a uma pequena fração da burguesia nacional e internacional.

Azevedo (1999) afirma que a busca do desmantelamento do Estado Social ocasiona graves problemas, propositadamente não referidos ou subestimados. A flexibilização dos direitos sociais é apresentada como indispensável e contrária à rigidez impeditiva do livre jogo das forças econômicas. Destroem-se os serviços públicos na ânsia de privatizá-los, vale dizer, comprá-los a bom preço para auferir lucros imediatos (AZEVEDO, 1999, p. 114-115).

${ }^{12}$ A Constituição Federal de 1988 foi escrita para ser um documento definitivo no ordenamento jurídico brasileiro e isso a obrigava a reconhecer que haveria, ao longo do tempo, situações que deveriam ser adicionadas ou modificadas em seu conteúdo. Para isto, existe a PEC. A sigla significa Projeto de Emenda Constitucional, que pode representar uma adição ou modificação ao texto da Constituição original da Lei Maior, sem que sejam feridos os seus princípios básicos. Por tratar de uma modificação na lei mais importante do ordenamento jurídico nacional, a aprovação é (e deve ser) um processo extremamente burocrático, que passa por uma série de avaliações para definir se ela é válida, necessária e de acordo com as demandas do país (O QUE, [s. d.]). 
Candiotto (2012) afirma que esse é o caso do estado brasileiro no qual os direitos sociais garantidos constitucionalmente pelo processo da redemocratização foram negligenciados, uma clara demonstração de que a política tornou-se governada pela lógica acumulativa do capital e seus imperativos.

\title{
4 CORONAVÍRUS: O FRACASSO NEOLIBERAL E A ADOÇÃO DE MEDIDAS DE BEM-ESTAR SOCIAL
}

A expansão do neoliberalismo contribuiu para o fato de que, desde os anos 80 do século XX, o mundo passou por quatro grandes epidemias (ebola, SARS, MERS e agora covid19), sendo a aplicação de suas políticas - ou seja, desregulamentação dos mercados e sua globalização, bem como políticas de austeridade social - um dos fatores que mais contribuíram para a disseminação de tais doenças.

Conforme Harvey (2020, p. 17), conceituado geógrafo marxista, explicita:

\begin{abstract}
Quarenta anos de neoliberalismo na América do Norte e do Sul e na Europa tinham deixado o público totalmente exposto e mal preparado para enfrentar uma crise de saúde pública deste tipo, apesar dos riscos anteriores da SARS e do Ebola terem fornecido abundantes avisos, bem como lições convincentes sobre o que seria necessário fazer (HARVEY, 2020, p. 17).
\end{abstract}

De acordo com Bihr (2020, p. 27), o fracasso prático das políticas neoliberais de saúde não deve apenas dar-nos a oportunidade de denunciar a falência dos seus fundamentos ideológicos, elas também:

\footnotetext{
Abrem uma brecha para que nós (as forças anti-capitalistas, associativas, sindicais e políticas) aproveitemos, denunciando a responsabilidade dos governantes, presentes e passados, que conduziram essas políticas que nos levaram ao desastre atual, do qual a população que está pagando o preço está cada vez mais claramente consciente. Invertendo o postulado destas políticas, defendendo a ideia de que a saúde é, antes de tudo, um bem público e que, portanto, deve ser da atribuição dos poderes públicos, podemos pensar em propor, no que diz respeito à França (BIHR, 2020, p. 27).
}

Badiou (2020) aponta que a pandemia tem exposto as fragilidades do modelo neoliberal, na medida em que as intervenções do Estado são fundamentais para a contenção do novo coronavírus. A pandemia da COVID-19 vem apontando as falhas do sistema em que vivemos, que alcançaram sua máxima expressão nos sistemas de saúde. As novas e grandes intervenções dos Estados para recuperar ou, ao menos, tentar paliar as desastrosas consequências da pandemia sobre a economia (além de sua maior e decisiva intervenção em 
outras áreas como a saúde e a assistência social) não supõe necessariamente que este "voltou para ficar". Como sustenta Badiou (2020), as tentativas dos Estados nacionais de lidarem frente à epidemia são feitas respeitando todos os mecanismos do capital. Ainda que isso não deva se confundir com o fato de que estão atuando sob ordens diretas das grandes empresas.

Neste contexto, a pandemia do coronavírus se tornou uma oportunidade para evidenciar que a desigualdade social traz reflexos perversos para toda a sociedade no país. São inúmeros os desafios das cidades brasileiras em decorrência da forte urbanização, fragmentação territorial e das enormes desigualdades socioespaciais que marcam a vulnerabilidade e inúmeros problemas de saúde, um fenômeno latino-americano (ROLNIK, 2013).

Muitos dos habitantes das periferias urbanas residem em locais muito precários: moradias com um ou dois cômodos, pouca ventilação, frequentemente compartilhadas por um número grande de pessoas. A maior parte das famílias não tem como isolar as pessoas sintomáticas por causa do espaço, algumas casas possuem apenas um ou dois cômodos. Gomes (2006) afirma que a aglomeração é extremamente comum nas famílias de baixa renda, devido à elevada taxa de natalidade. Esse fator, aliado às precárias condições de moradia, levam a um aumento na incidência de doenças.

Em grande parte dos domicílios faltam condições para adquirir produtos que garantam a desinfeç̧ão das mãos, como o álcool gel, que não estão ao alcance de muitos moradores de comunidades e periferias das cidades brasileiras. Essa regra é geral e tem sido propagada diariamente por governos, pela imprensa e por especialistas na área de saúde. Além disso, poucos moradores podem aderir ao isolamento, conforme recomendação da Organização Mundial da Saúde (OMS). Pessoas de menor renda e trabalhadores informais são os mais afetados pelos efeitos econômicos da pandemia. Sem acesso à saúde, ao saneamento e sem emprego um grande número de trabalhadoras e trabalhadores brasileiros está muito mais suscetível à contaminação.

Um sintoma de como a pandemia do coronavírus colocou em xeque o neoliberalismo foi o fato de que, em meio ao isolamento social, o Banco Mundial e o Fundo Monetário Internacional passaram a recomendar que os países apresentassem planos fiscais de recuperação econômica, com recursos expressivos para as áreas de saúde e de proteção de populações mais vulneráveis. Na Alemanha, por exemplo, o governo passou a cogitar a 
expansão da dívida pública e do déficit fiscal; nos Estados Unidos, o governo adotou o discurso da participação do Estado na economia, além disso, houve liberação de caixa para atender demandas de empresas e populações vulneráveis; na Espanha, hospitais foram estatizados e as iniciativas públicas valorizadas.

É importante ressaltar que países que não adotam medidas neoliberais como China e Coréia do Sul, Taiwan e Singapura, tenham atravessado até agora a pandemia melhor do os países que possuem sua economia baseada na austeridade fiscal e na baixa intervenção do Estado na economia.

Não há consenso sobre o regime de produção existente na China, mas é possível indagar sobre a existência de um capitalismo de Estado, um sistema de dominação estatalburocrático no país (DEUTSCHER, 2008). A China vive um "socialismo de mercado ou um socialismo com características chinesas" (JABBOUR, 2012, p. 79). Isso porque o processo de construção socialista no país é caracterizado pela centralidade de uma superestrutura de poder que difere das existentes no centro e periferia do sistema capitalista por concentrar duas ferramentas essenciais para a produção: o planejamento e a propriedade dos setores estratégicos, com alto grau de monopólio da economia nacional. Ela é hoje um país importante no que se refere à criação tecnológica, industrialização acelerada, altas taxas de crescimento do produto, desenvolvimento de um Estado de bem-estar social, entre outras características desejáveis. Entretanto, a República Popular da China (RPC) ainda é marcada pela enorme presença do Partido Comunista, que controla a maior parte das atividades sociais e econômicas, inclusive com a participação de empresários (JABBOUR, 2012).

Diferentemente das experiências europeias, a elevação dos gastos estatais com bem-estar ocorre em um cenário de queda da taxa de desemprego. Além disso, enquanto a globalização motivou cortes de gastos com bem-estar nos estados europeus, ela acabou sendo um fator para a expansão do sistema de welfare no país (SCHMIDT, 2012).

\section{CONSIDERAÇÕES FINAIS}

A crise provocada pelo coronavírus vem revelando a fragilidade de um modelo socioeconômico que parecia infalível. A pandemia atual não teria o impacto que tem senão fosse por três longas décadas de neoliberalismo, que causou danos sociais provavelmente irreparáveis. 
A pandemia da Covid-19 é consequência das medidas que começaram a ser adotadas nos anos oitenta do século passado, quando a maior parte dos governos do mundo abraçou o neoliberalismo e a sua doutrina que proclamava uma drástica redução dos gastos públicos e desmantelamento da intervenção do Estado nos programas sociais. Desta maneira, se criou uma cultura em que o lucro estava por cima de tudo e de todos; onde valia o corte dos recursos humanos dos sistemas de saúde, tanto nacionais quanto internacionais, e onde se banalizaram uma série de acontecimentos recentes como a Aids, a Dengue, o Ebola e o Zika vírus.

A pandemia do coronavírus vem apontando a precariedade do neoliberalismo, mas ainda é muito cedo para determinar a extensão e a profundidade que a crise sanitária alcançará em nível global. Desde a chegada do coronavírus no Brasil, a agenda de redução do tamanho do Estado se inverteu e o governo está sendo autorizado pelo Congresso a descumprir metas fiscais e descontinuar medidas que visavam à redução do déficit público, como o teto de gastos para lidar com as necessidades impostas pela pandemia.

Com o avanço do coronavírus, há um reposicionamento do papel do Estado, que a partir da crise, vem adotando práticas de gestão políticas baseadas no Welfare State, um modelo social, político e econômico solidário que garanta a todos os cidadãos, independentemente da idade ou classe social, padrões mínimos de saúde e seguridade social. Sem a pretensão de esgotar a análise do tema proposto, este artigo buscou apontar a importância do Estado de bem-estar na China como fator fundamental para o controle do coronavírus.

\section{REFERÊNCIAS}

ANDERSON, P. Balanço do neoliberalismo. In: SADER, Emir; GENTILI, Pablo (orgs.) Pósneoliberalismo: as políticas sociais e o estado democrático. São Paulo: Paz e Terra, 1995. p. 9-23.

AZEVEDO, P. F. de. Direito, justiça social e neoliberalismo. São Paulo: Revista dos Tribunais, 1999.

BADIOU: Sobre a situação epidêmica. Blog da Boitempo, [S. I.], 2020. Disponível em: https://blogdaboitempo.com.br/2020/04/08/badiou-sobre-a-situacao-epidemica/. Acesso em: 17 abr. 2020. 
BEHRING, E. Política social no contexto da crise capitalista. In: CONSELHO FEDERAL DE SERVIÇO SOCIAL; ASSOSSIAÇÃO BRASILEIRA DE ENSINO E PESQUISA EM SERVIÇO SOCIAL. Serviço Social: direitos sociais e competências profissionais. Brasília: CFESS/ ABEPSS, 2009.

BIHR, A. Pour une socialisation de l'appareil sanitaire (le cas de la France).

In: DAVIS, Mike et al. Coronavírus e a luta de classes. Brasil: Terra sem Amos, 2020.

CANDIOTTO, C. Neoliberalismo e democracia. Princípios: revista de filosofia (UFRN), [S. I.], v. 19, n. 32, p. 153-179, jun./dez. 2012. Disponível em: https://periodicos.ufrn.br/principios/article/view/7568. Acesso em: 5 jan. 2020.

DEUTSCHER, I. Marxismo, guerras e revoluções: ensaios de quatro décadas. São Paulo: Editora Ática, 2008.

FALEIROS, V. P. A reforma do estado no período FHC e as propostas do governo Lula. INESC, [S. I.], p. 35-55, 2004.

FIORI, J. L. Globalização, hegemonia e império. In: FIORI, J. L. (org.). Estados e moedas no desenvolvimento das nações. Petrópolis: Vozes, 1997.

ESPING-ANDERSEN, G. The Three Worlds of Welfare Capitalism. Princeton University Press, New Jersey, c1990.

FILGUEIRAS, L. História do Plano Real: fundamentos, impactos e contradições. São Paulo: Boitempo, 2003.

FUKUYAMA, F. O Fim da História e o Último Homem. São Paulo: Rocco, 1992.

GOMES, F. G. Conflito social e welfare state: Estado e desenvolvimento social no Brasil. Revista de Administração Pública, v. 40, n. 2, p. 201-234, 2006. Disponível em: https://www.scielo.br/scielo.php?script=sci_abstract\&pid=S0034-

$76122006000200003 \&$ Ing=pt\&nrm=iso\&tlng=pt. Acesso em: 5 jan. 2020.

HARVEY, D. Política Anticapitalista em Tempos de COVID-19. In: DAVIS, Mike et al. Coronavírus e a luta de classes. Brasil: Terra sem Amos, 2020.

JABBOUR, E. China hoje: projeto nacional, desenvolvimento e socialismo de mercado. São Paulo: Anita Garibaldi: Fundação Maurício Grabois; Paraíba: EDUEPB, 2012.

LANA, R. M. Emergência do novo coronavírus (SARS-CoV-2) e o papel de uma vigilância nacional em saúde oportuna e efetiva. Cadernos de Saúde Pública, Rio de Janeiro, v. 36, n. 3, 2020. Disponível em: https://www.scielo.br/scielo.php?script=sci_arttext\&pid=S0102311X2020000300301. Acesso em: 5 jan. 2020.

LEME, A. A. Neoliberalismo, globalização e reformas do estado: reflexões acerca da temática. Barbaroi, Santa Cruz do Sul, n. 32, jan./jul. 2010. Disponível em: 
https://www.researchgate.net/publication/263258084_Neoliberalismo_globalizacao_e_refo rmas_do_estado_reflexoes_acerca_da_tematica. Acesso em: 5 jan. 2020.

LOBATO, L. de V. C. Políticas sociais e modelos de bem-estar social: fragilidades do caso brasileiro. Saúde debate, Rio de Janeiro, v. 40, n. especial, p. 87-97, dez. 2016. Disponível em: https://www.scielo.br/scielo.php?pid=S0103-

11042016000500087\&script=sci_abstract\&tlng=pt. Acesso em: 5 jan. 2020.

LOPES, C. Crescimento econômico e desigualdade: As novidades pós-Consenso de Washington. Revista Crítica de Ciências Sociais, v. 94, número não temático, 2011. Disponível em: https://journals.openedition.org/rccs/1475. Acesso em: 5 jan. 2020.

MADEIRO, Â.T. Financiamento das políticas públicas, especificidade da assistência social: um estudo do FMAS (fundo municipal de assistência social) do município de Fortaleza no período de 2006 a 2009. 2013. Dissertação (Mestrado Acadêmico Em Políticas Públicas E Sociedade) - Centro De Ciências Sociais Aplicadas, Universidade Estadual do Ceará, Fortaleza, 2013. Disponível em: http://uece.br/politicasuece/dmdocuments/angela_madeiro.pdf. Acesso em: 5 jan. 2020.

MARX, K. Contribuição a crítica da economia política. 2. ed. São Paulo: Expressão Popular, 2008. Disponível em:

https://gpect.files.wordpress.com/2013/11/contribuicao_a_critica_da_economia_politica.p df. Acesso em: 5 jan. 2020.

MENEZES, P. Um plano de combate à pandemia proposto por conservadores americanos. Gazeta do Povo, [S. I.], 2020. Disponível em: https://www.gazetadopovo.com.br/vozes/pedro-menezes/um-plano-de-combate-apandemia-proposto-por-conservadores-americanos/. Acesso em: 17 abr. 2020.

MISHRA, R. Society and Social Policy: theories and practice of welfare. London: Basingstoke: The Macmillan Press, 2018.

MOTTA, R. P. S. Em guarda contra o perigo vermelho: o anticomunismo no Brasil (19171964). São Paulo: Perspectiva: Fapesp, 2002.

O QUE é uma PEC e como funciona?. Direitos Brasil, [S. I.: s. d.]. Disponível em: http://direitosbrasil.com/pec-o-que-e-e-como-funciona/. Acesso em: 5 jan. 2020.

REIS, F. W. Estado Liberal, Projeto Nacional, Questão Social. In: REIS, F. W. Mercado e Utopia. Rio de Janeiro: Centro Edelstein de Pesquisas Socais, 2009. p. 418-444. Disponível em: http://books.scielo.org/id/v7ywf/pdf/reis-9788599662793-15.pdf. Acesso em: 5 jan. 2020.

RODRIGUES, A. Políticas Sociais e Política de Saúde. Revista Discente do Progrma de PósGraduação em História, v. 2, n. 3, jan./jun. 2016. Disponível em: https://www.ufjf.br/facesdeclio/files/2014/09/3.Artigo-D9.Adebiano.pdf. Acesso em: 5 jan. 2020. 
ROLNIK, R. Late neoliberalism: the financialization of homeownership and housing rights. International Journal of Urban and Regional Research, v. 37, n. 3, p. 1058-1066, 2013. Disponível em: https://onlinelibrary.wiley.com/doi/abs/10.1111/1468-2427.12062. Acesso em: 5 jan. 2020.

SCHMIDT, S. China - A welfare state?: the development of the welfare effort in a multidimensional context. 2012. 47 f. Trabalho de Conclusão de Curso (Graduação em Administração) - Faculty Of Management And Governance, University Of Twente, Enschede, 2012.

STRECK, L. L.; BOLZAN DE MORAIS, J. L. Ciência política e teoria do estado. 7. ed. Porto Alegre: Livraria do Advogado, 2010.

VIANA, A. L.; LEVCOVITZ, E. Proteção social: introduzindo o debate. In: VIANA, A. L.; ELIAS. P.; Ibañez, N. (Orgs.). Proteção social: dilemas e desafios. São Paulo: Hucitec, 2010. p. 15-57. 